\title{
SISTEM DETEKSI WAJAH JENIS KUCING DENGAN IMAGE CLASSIFICATION MENGGUNAKAN OPENCV
}

\author{
Muhammad Ridwan Effendi \\ Program Studi/Jurusan Sistem Informasi \\ Univeristas Mohammad Husni Thamrin Jakarta \\ Jl. Raya Pd. Gede No. 23-25, Jakarta, Indonesia \\ emaill : jundi79@gmail.com
}

\begin{abstract}
Abstrak - Banyaknya ras kucing yang diakui secara jenis klasifikasi diantaranya seperti Anggora, Persia, kucing local dan lain lain. Setiap ras memiliki ciri khusus, maka penentuan ras kucing asli menjadi sulit. Dikarenakan kurangnya informasi tentang membedakan klasifikasi jenis kucing. Maka penulis menganalisa identifikasi dan mengenali jenis kucing Anggora dan Persia melalui bentuk hidung dan wajah dan kaki yang dapat diambil melalui image dengan menggunakan OpenCV (Open Source Computer Vision Library). Metode penelitian berupa pengamatan langsung, pengumpulan data objek, dan studi pustaka (Library Research) dengan menggunakan perangkat lunak Visual Studio dan Library OpenCV dan Python. Dalam menggunakan metode image classification karena klasifikasi citra
\end{abstract}

\section{Pendahuluan}

Banyaknya ras kucing yaitu sekitar 32 kucing yang diakui secara internasional diantaranya seperti Anggora dan Persia. Kucing Anggora berasal dari angora sebuah kota di Turki. Kota Angora sejak tahun 1930 disebut dengan Ankara Kedisi. Jika di lihat kucing Anggora mirip dan hampir sama dengan kucing Persia, tetapi bila kita perhatikan secara seksama maka akan tampak jelas perbedaannya pada hidung, badan dan bulunya. Kucing Persia mempunyai ciri berhidung pesek, berbadan agak membulat dan sekujur badannya berbulu panjang. Sedangkan kucing Anggora biasanya berhidung mancung, berbadan agak ramping dan bulunya panjang pada bagian-bagian tertentu saja. Pada pengembangan teknologi pengenalan wajah yaitu dengan menambah tingkat kecepatan dan akurasi dalam pendeteksian wajah. Banyak dari sistem pendeteksian tersebut menggunakan metode Viola Jones (viola, 2001) sebagai metode pendeteksi objek. Metode Viola Jones dikenal memiliki kecepatan dan keakuratan yang cukup tinggi karena menggabungkan beberapa konsep (Fitur Haar, Citra Integral, AdaBoost, Cascade Classifier) menjadi sebuah metode utama untuk mendeteksi objek. Pada penelitian ini akan dijelaskan mengenai cara kerja Viola Jones, dalam sistem deteksi wajah jenis kucing dengan memanfaatkan librari Open $C V$ dan merupakan suatu proses pengelompokan seluruh pixel pada suatu citra kedalam kelompok sehingga dapat diinterpretasikan sebagai suatu property yang spesifik. Metode image Classification menggunakan dua algoritma yaitu Haarcascade dan Viola Jones. Haarcascade yaitu Haar Classifier merupakan pengklasifikasian fitur yang digunakan dalam metode viola jones. Viola Jones merupakan metode yang paling banyak digunakan untuk mendeteksi objek hal ini dikarenakan viola jones memiliki algoritma yang efisien. Hasil analisa riset penulis pada pendeteksian gambar menggunakan Python dan untuk menampilkan image dengan menggunakan opencv.

\section{Kata kunci: Kucing, Opencv, Image Classification, Pengolahan Citra}

Python. Setelah sistem selesai dibuat, akan dibahas mengenai cara kerja sistem deteksi mulai dari akuisisi citra, pengolahan citra, pengenalan pola, dan analisis citra. Kemudian dilakukan pengujian mengenai karakter wajah yang dapat dideteksi.

\section{Image Classification}

Citra (image) adalah gambar pada bidang dwimatra (dua dimensi). Ditinjau dari sudut pandang matematis, citra merupakan fungsi menerus (continue) dari intensitas cahaya pada bidang dwimatra. Sumber cahaya menerangi objek, objek memantulkan kembali sebagian dari berkas cahaya tersebut. Pantulan cahaya ini ditangkap oleh oleh alat-alat optik, misalnya mata pada manusia, kamera, pemindai (scanner), dan sebagainya, sehingga bayangan objek yang disebut citra tersebut terekam. (Andi, 2016).

Klasifikasi citra merupakan suatu proses pengelompokan seluruh pixel pada suatu citra kedalam dalam kelompok sehingga dapat diinterpretasikan sebagai suatu property yang spesifik (H.Ren., 2000) Ada dua metode umum dalam mengidentifikasi dan mengklasifikasikan citraan satelit yaitu klasifikasi tak terbimbing dan klasifikasi terbimbing yang berkaitan dengan paendekatan dalam pengenalan pola.

\section{Pengolahan Citra Awal}

Proses ketika citra non-digital diubah ke citra 
digital. Citra digital diperoleh dari hasil digitisasi citra analog. Digitisasi citra melibatkan dua proses, yaitu sampling dan kuatisasi. Sampling menunjukkan banyaknya pixel/blok untuk mendefinisikan suatu gambar. Kuantisasi menunjukkan banyaknya derajat nilai pada setiap pixel (menunjukkan jumlah bit pada gambar digital, black/white dengan 2 bit, grayscale dengan 8 bit, true color dengan 24 bit). Pengolahan Citra dilakukan untuk memperbaiki kualitas citra agar mudah untuk diinterpretasi oleh manusia/komputer. Masukannya adalah citra dan keluarannya juga citra, tetapi dengan kualitas lebih baik daripada citra masukan. Operasi pengolahan citra yang berhubungan dalam deteksi wajah: grayscaling, neighborhood operation, thresholding, histogram equalization, resizing.

Proses analisis citra, dimulai dari pencitraan, sampai proses terakhir, sehingga didapat sebuah keputusan untuk maksud atau tujuan tertentu. Pada penelitian ini lebih focus bagaimana menentukan wajah jenis kucing di antara background.

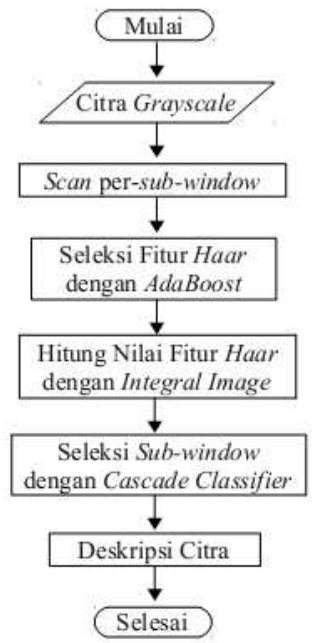

Gambar 1. Diagram Alir Metode Viola Jones

\section{Algoritma}

Analisis algoritma dilakukan untuk dapat mengetahui alur proses dari algoritma yang digunakan dan dapat diterapkan kedalam sistem perangkat lunak. Dalam proses pendeteksian ini menggunakan library dalam OpenCV. Pada pendeteksian wajah (face detetection) kucing pada perangkat lunak ini menggunakan metode viola-jones Serta dibantu oleh algoritma Local Binari Pattern Histograms (LBPH) untuk pelabelan gambar (face recognition). Berikut ini adalah tahap-tahap yang dilakukan untuk mendeteksi ras kucing, yaitu

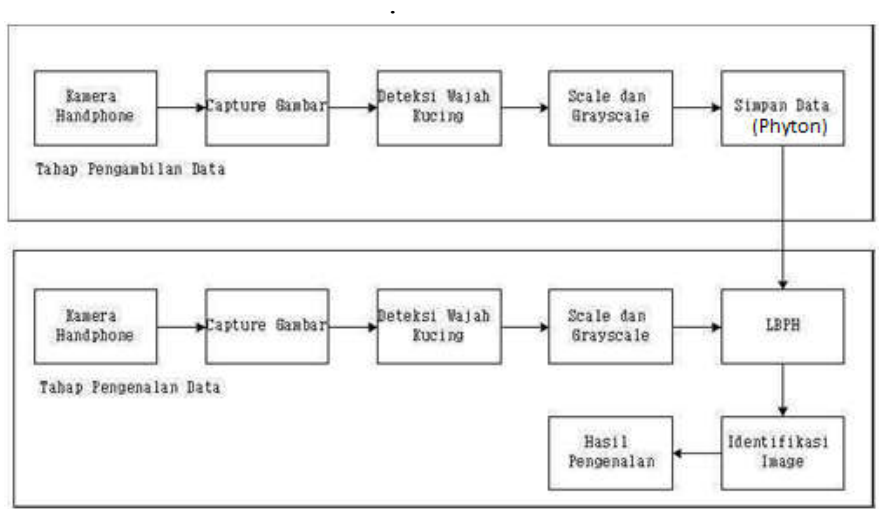

Gambar 2. Blok Diagram System

Blok diagram software untuk melakukan pengenalan dari sistem yang digunakan, dimana jalannya sistem dibagi menjadi 2, yaitu blok penyimpanan data dan blok pengenalan wajah. Jalannya sistem blok diagram adalah sebagai berikut :

1. Pengambilan gambar secara real-time menggunakan kamera digital dan kamera pada handphone.

2. Proses deteksi kucing menggunakan algoritma Viola-Jones dengan haar cascade.

3. Proses penskalaan (scaling) dan grayscale.

4. Proses penyimpanan data gambar kucing berdasarkan ras.

5. Proses pengenalan dengan Local Binary Pattern Histogram (LBPH).

Objek wajah dicari menggunakan Viola Jones yang mengacu alur seperti pada Gambar 1, dimana citra grayscale akan di-scan per-sub-window untuk dicari fitur positif dengan AdaBoost dan Cascade Classifier. Jika wajah terdeteksi, akan dilakukan penggambaran garis persegi pada wajah tersebut.Pendeteksian objek menggolongkan gambar berdasarkan pada nilai dari fitur sederhana. Operasi dasar dari suatu fitur jauh lebih cepat dibandingkan dengan pengolahan pixel. Sejumlah Fitur Haar mewakili wilayah persegi pada citra dan menjumlahkan semua piksel pada daerah tersebut. Viola Jones mengklasifikasikan citra dari nilai fitur-fitur sederhana dan menggunakan tiga jenis fitur, yaitu fitur persegi, fitur tiga persegi, dan fitur empat persegi. Nilai dari fitur-fitur tersebut adalah selisih antara daerah hitam dan putih.

Di dalam tiap sub-window image, jumlah total dari Fitur Haar sangat besar, jauh lebih besar jika dibandingkan dengan jumlah pixel. Untuk memastikan pengklasifikasian dapat dilakukan secara cepat, proses pembelajaran harus menghilangkan fiturfitur mayoritas yang tersedia, dan memusatkan pada sekumpulan kecil fitur yang perlu. AdaBoost bertujuan untuk membentuk template wajah. 
Suatu metode klasifikasi yang menggunakan beberapa tingkatan dalam penyeleksian. Pada tiap tingkatan dilakukan penyeleksian menggunakan algoritma AdaBoost yang telah di-training dengan menggunakan Fitur Haar. Penyeleksian berguna untuk memisahkan antara sub-window yang mengandung positif objek (gambar yang terdeteksi memiliki objek yang diinginkan) dengan negatif objek (gambar yang terdeteksi tidak memiliki objek yang diinginkan).

\section{Haar Cascade}

Setelah training data telah dilakukan, selanjutnya memanggil algoritma Haar Cascade dalam program. Pelacakan wajah pada penelitian ini dikhususkan untuk pelacakan wajah dengan posisi lurus ke depan terhadap kamera (frontal face). Dan berikut ini contoh dan proses-proses yang terjadi dalam metode haar cascade.

Contoh Metode Haar Cascade yaitu :

1. Deteksi wajah

2. Deteksi tepi dan lain lainnya

\section{Local Binari Pattern Histograms (LBPH)}

Local Binary Pattern Histogram (LBPH) adalah fitur untuk mengklasifikasi yang dikombinasikan dengan histogram dan merupakan teknik baru dari metode LBP untuk mengubah performa hasil pengenalan wajah. LBPH pada umumnya didesain utuk pengenalan tekstur. LBPH adalah metode yang paling cocok untuk dilakukan pengenalan citra wajah untuk diimplementasikan pada perangkat bergerak android karena menggunakan penghitungan yang sederhana mengingat resource android yang terbatas (Wijaya, 2014).

Pada pengenalan wajah ini digunakan algoritma Local Binari Pattern Histograms (LBPH). Local Binary Pattern Histogram (LBPH) adalah teknik baru dari metode LBPH untuk mengubah performa hasil pengenalan wajah. LBPH adalah metode yang paling cocok untuk dilakukan pengenalan citra wajah. Mekanismenya adalah pertama-tama membagi daerah gambar menjadi $8 \times 8$. citra, sehingga waktu yang dibutuhkan untuk melakukan proses selanjutnya berjalan lebih cepat. Hal ini bisa dilakukan karena perhitungan yang terjadi hanya dilakukan pada satu layer saja, yaitu layer derajat keabuan. Pada umumnya warna yang dipakai warna hitam sebagai warna minimal (0) dan warna putih (255) sebagai warna maksimalnya, sehingga warna antaranya adalah abu-abu, seperti ditunjukkan pada Gambar 4 .

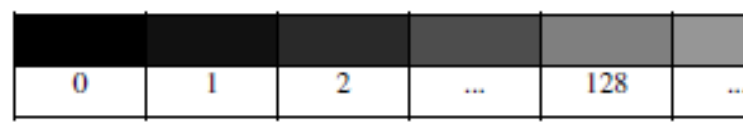

\section{GAMBAR 4 PALLETE SKALA GRAYSCALE}

Derajat keabuan sendiri sebenarnya memiliki beberapa nilai, tidak hanya skala 0 sampai 255 . Hal ini tergantung pada nilai kedalaman pixel yang dimiliki oleh citra. Misalnya dalam gambar kucing yang telah dicapture mempunyai nilai warna Red, Green dan Blue seperti pada Tabel 1 .

\begin{tabular}{|c|c|c|c|c|c|c|c|c|c|c|c|}
\hline $\mathrm{X} / \mathrm{y}$ & & 0 & 1 & 2 & 3 & 4 & 5 & 6 & 7 & 8 & 9 \\
\hline O & $\mathrm{R}$ & 210 & 215 & 209 & 220 & 220 & 207 & 203 & 192 & 208 & 209 \\
& $\mathrm{G}$ & 200 & 190 & 175 & 185 & 191 & 161 & 155 & 129 & 173 & 163 \\
& $\mathrm{~B}$ & 175 & 136 & 104 & 121 & 135 & 84 & 79 & 52 & 115 & 88 \\
\hline 1 & $\mathrm{R}$ & 212 & 221 & 228 & 222 & 216 & 214 & 207 & 209 & 193 & 193 \\
& $\mathrm{G}$ & 185 & 192 & 202 & 196 & 189 & 173 & 171 & 173 & 130 & 143 \\
& $\mathrm{~B}$ & 132 & 136 & 145 & 145 & 142 & 107 & 113 & 123 & 61 & 72 \\
\hline. & & & & & & & & & & & \\
. & & & & & & & & & & & \\
. & & & & & & & & & & & \\
\hline 9 & $\mathrm{R}$ & 212 & 221 & 228 & 222 & 216 & 214 & 207 & 209 & 193 & 193 \\
& $\mathrm{G}$ & 185 & 192 & 202 & 196 & 189 & 173 & 171 & 173 & 130 & 143 \\
& $\mathrm{~B}$ & 132 & 136 & 145 & 145 & 142 & 107 & 113 & 123 & 61 & 72 \\
\hline
\end{tabular}

\section{TABel 1 NiLAi GAMBAR WARNA CAPTURE}

Menurut (Munir R. , 2010, p. 194) Untuk mendapatkan citra grayscale, kita bisa menggunakan rumus dibawah ini :

$$
s=\frac{r+g+b}{3}
$$

Dimana $\mathbf{r}, \mathbf{g}, \mathbf{b}=$ nilai Red, Green, dan Blue $\mathbf{s}=$ nilai grayscale menjadi

\section{GAMBAR 3 CAPTURE}

\section{Grayscale}

Grayscale yaitu mengubah citra RGB menjadi citra keabuan yang digunakan untuk menyederhanakan model

\begin{tabular}{|c|c|c|c|c|c|c|c|c|c|c|}
\hline $\mathrm{x} / \mathrm{y}$ & 0 & 1 & 2 & 3 & 4 & 5 & 6 & 7 & 8 & 9 \\
\hline 0 & 195 & 180 & 163 & 175 & 182 & 151 & 146 & 124 & 165 & 153 \\
\hline 1 & 176 & 183 & 192 & 188 & 182 & 165 & 164 & 168 & 128 & 136 \\
\hline$\cdot$ & & & & & & & & & & \\
$\cdot$ & & & & & & & & & & \\
$\cdot$ & & & & & & & & & & \\
\hline 9 & 176 & 183 & 192 & 188 & 182 & 165 & 164 & 168 & 128 & 136 \\
\hline
\end{tabular}

TABel 2 Nilai Grayscale Hasil Perhitungan 
Scaling atau penskalaan citra merupakan suatu proses pengubahan ukuran citra baik itu memperkecil maupun memperbesar ukuran citra. dalam hal ini memperbesar dan memperkecil gambar, biasanya ukuran untuk proses pendeksian wajah yang efektif menggunakan pixel 20x20. Misalkan gambar yang telah dicapture mempunyai nilai value :

\begin{tabular}{|c|c|c|c|c|c|c|c|c|c|}
\hline $\mathrm{x} / \mathrm{y}$ & 0 & 1 & 2 & 3 & 4 & 5 & 6 & 7 & \\
\hline 0 & 195 & 180 & 163 & 175 & 182 & 151 & 146 & 124 & \\
\hline 1 & 176 & 183 & 192 & 188 & 182 & 165 & 164 & 168 & \\
\hline$\cdot$ & & & & & & & & & Def \\
$\cdot$ & & & & & & & & & \\
$\cdot$ & & & & & & & & & \\
\hline 9 & 176 & 183 & 192 & 188 & 182 & 165 & 164 & 168 & \\
\hline
\end{tabular}

Dikarenakan gambar berukuran 10x10 maka gambar harus diskala sehingga menjadi 20x20. Untuk mendapatkan scaling atau penskalaan citra dapat menggunakan rumus seperti di bawah ini:

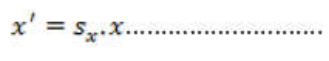

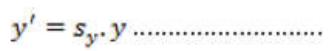

sx dan sy adalah faktor skala masing-masing dalam arah $\mathrm{x}$ dan arah $\mathrm{y}$. Maka $\mathrm{Sx}=2$ dan $\mathrm{Sy}=2$.

\begin{tabular}{|l|l|}
\hline 195 & 180 \\
\hline 176 & 183 \\
\hline
\end{tabular}

Karena ukuran gambar diperbesar maka nilai dua petak tetanggannya mempunyai nilai yang sama sehingga menghasilkan :

\begin{tabular}{|c|c|c|c|c|c|c|c|c|c|c|c|c|c|c|}
\hline$x / y$ & 0 & 1 & 2 & 3 & 4 & 5 & 6 & 7 & 8 & 9 & 10 & 11 & 12 & 13 \\
\hline 0 & 195 & 195 & 180 & 180 & 163 & 163 & 175 & 175 & 182 & 182 & 151 & 151 & 146 & 146 \\
\hline 1 & 195 & 195 & 180 & 180 & 163 & 163 & 175 & 175 & 182 & 182 & 151 & 151 & 146 & 146 \\
\hline 2 & 176 & 176 & 183 & 183 & 192 & 192 & 188 & 188 & 182 & 182 & 165 & 165 & 164 & 164 \\
\hline 3 & 176 & 176 & 183 & 183 & 192 & 192 & 188 & 188 & 182 & 182 & 165 & 165 & 164 & 164 \\
\hline
\end{tabular}

TABEl 4 Nilai SCAle Hasil PERHITUNGAN

\section{Open CV dan Python}

Open Computer Vision (OpenCV) sendiri merupakan library open source yang tujuannya dikhususkan untuk melakukan pengolahan citra. Maksudnya adalah agar komputer mempunyai kemampuan yang mirip dengan cara pengolahan visual pada manusia. OpenCV telah menyediakan banyak algoritma visi komputer dasar. Open $C V$ juga

menyediakan modul pendeteksian objek yang menggunakan algoritma Viola Jones.

Python adalah salah satu bahasa pemograman tingkat tinggi yang bersifat interpreter, interactive, objectoriented, dan dapat beroperasi hampir di semua platform: Mac, Linux, dan Windows. Python termasuk bahasa pemograman yang mudah dipelajari karena sintaks9 yang jelas, dapat dikombinasikan dengan perggirsaan modul- modul siap pakai, dan struktur daka tingkat tinggi yang efisien (Kadir, 2005).

Distribusi Python dilengkapi dengan suatu fasilitas seperti shell di Linux. Lokasi penginstalan Python biasa terletak di “/usr/bin/Python", dan bisa berbeda. Menjakankan Python, cukup dengan mengetikan "Python", tunggu sebentar lalu muncul tampilan ">>>", berarti Python telah siap menerima perintah. Ada juga tanda “..." yang berarti baris berikutnya dalam suatu blok prompt '>>>'. Text editor digunakan untuk modus skrip.

Untuk membangun penelitian ini digunakan wxPython yang merupakan toolkit GUI untuk bahasa pemrograman Python. wxPython memungkinkan programmer Python untuk membuat aplikasi dengan pondasi kuat, grafis antarmuka dengan pengguna yang sangat fungsional, sederhana, dan mudah. wxPython diimplementasikan sebagai modul ekstensi oleh Python wxPython wxWidget GUI library

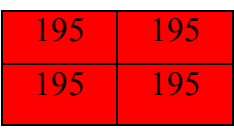

(kode membungkus sebagai salah satu populer yang ditulis dalam bahasa $\mathrm{C}++$. Selain itu, digunakan pula $\mathrm{Boa}$ Constructor yang merupakan Integrated Development Environment (IDE) untuk Python dan wxPython GUI Builder yang cross-platform. Boa Constructor mampu membuat, memanipulasi frame secara visual (tanpa skrip), dan ada banyak object inspector seperti: prowser objek, himarki warisan, debugger yang cânggî̀, dân bantuân yâng sudah terintegrasi.

\begin{tabular}{lll|l|l|l|l}
124 & 124 & 124 & 165 & 165 & 153 & 153
\end{tabular}

Metode Penelitian

Stuâtu24 125 prosecur 153 penelitian dibutuhkan agar perkerjan ${ }_{128}$ dapat ${ }_{136}$ dilakssanakan secara berurutan dan berkelanjutan tanpa harus mengganggu jenis 64 pekerjogan12aingya:13Penstapan meliputi segala sesuatu yang berhubungan dengan proses perancangan, yakni: mempelajari dan memahami cara Viola Jones bekerja, perancangan untuk algoritma dan flowchart, pembuatan sistem, kemudian menganalisis sistem.

Sistem yang akan dibuat mengacu diagam alir pada Gambar 3 dimana sistem setelah dijalankan untuk mengakuisisi citra, lalu dilakukan pengolahan citra: grayscaling, resizing, eqaulization. Wajah dicari menggunakan Viola Jones. Jika wajah terdeteksi, akan dilakukan penggambaran garis persegi pada wajah tersebut. 


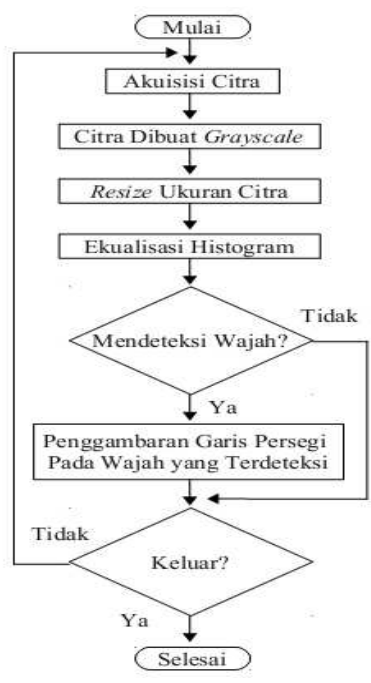

Gambar 4.

Diagram Alir

Sistem Deteksi

Wajah

\section{Hasil dan Pembahasan}

Untuk pendeteksian ras kucing dalam penelitian ini menggunakan gambar data ras kucing memiliki ciri-ciri sebagai berikut:

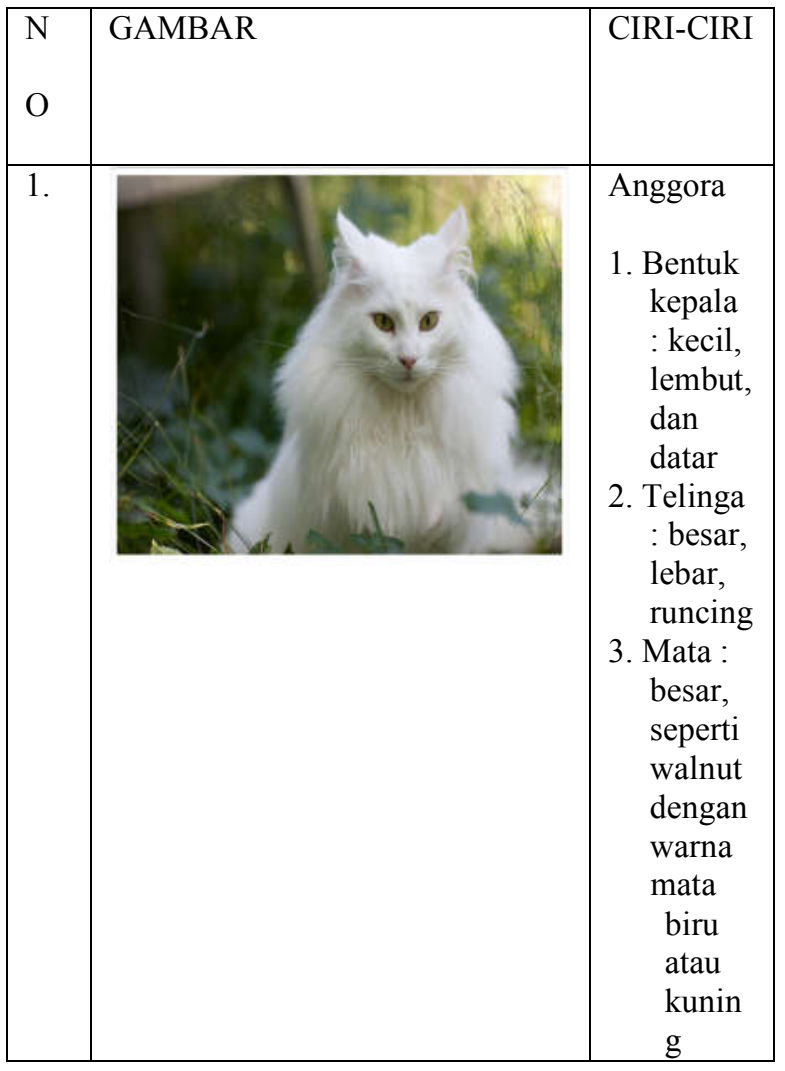

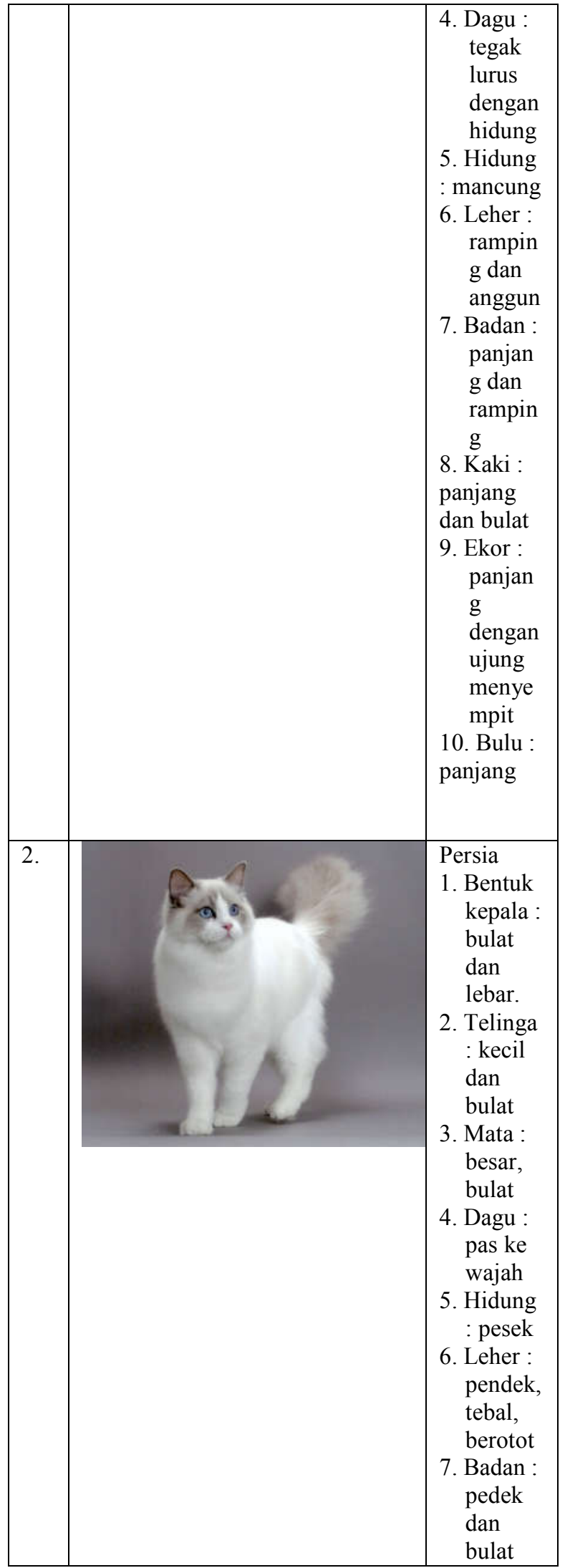




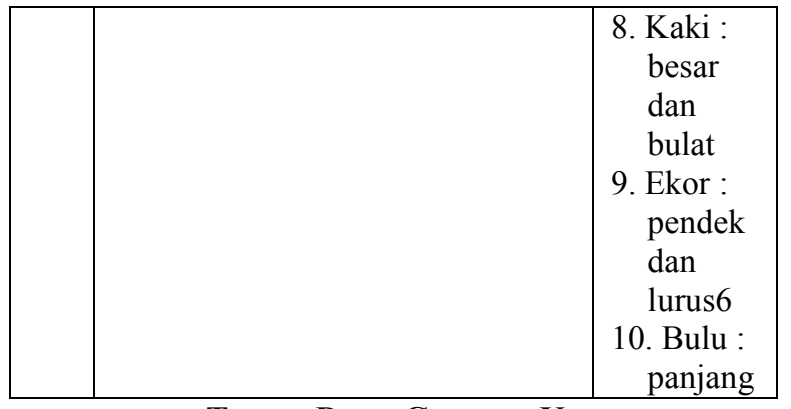

TABel Data Gambar KUCING

\section{Analisis}

Data gambar objek menjadi ke beberapa extension gambar seperti jpg, png, tif, bmp, yang dimasukan ke opencv.

Tabel Tabel Anggora

\begin{tabular}{|c|l|c|}
\hline No. & \multicolumn{1}{|c|}{ Variasi gambar } & Keterangan \\
\hline 1 & Hidung depan & Anggora \\
\hline 2 & Hidung samping kiri & Anggora \\
\hline 3 & Hidung samping kanan & Anggora \\
\hline 4 & Bentuk wajah depan & Anggora \\
\hline 5 & Bentuk wajah samping kiri & Anggora \\
\hline 6 & Bentuk wajah samping kanan & Anggora \\
\hline 7 & Kaki depan & Anggora \\
\hline 8 & Kaki samping kiri & Anggora \\
\hline 9 & Kaki samping kanan & Anggora \\
\hline
\end{tabular}

Tabel Tabel Persia

\begin{tabular}{|c|l|c|}
\hline No. & \multicolumn{1}{|c|}{ Variasi gambar } & Keterangan \\
\hline 1 & Hidung depan & Persia \\
\hline 2 & Hidung samping kiri & Persia \\
\hline 3 & Hidung samping kanan & Persia \\
\hline 4 & Bentuk wajah depan & Persia \\
\hline 5 & Bentuk wajah samping kiri & Persia \\
\hline 6 & Bentuk wajah samping kanan & Persia \\
\hline 7 & Kaki depan & Persia \\
\hline 8 & Kaki samping kiri & Persia \\
\hline 9 & Kaki samping kanan & Persia \\
\hline
\end{tabular}

\section{Hasil}

Dari 2 algoritma yang peneliti menggunakan metode viola jones karena lebih sangat efisien untuk menampilkan gambar sesuai ciri ciri klasifikasi.

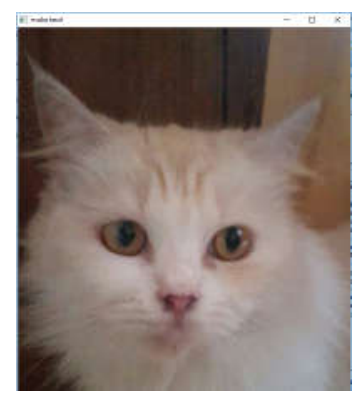

Gambar Hasil 1 muka depan angora

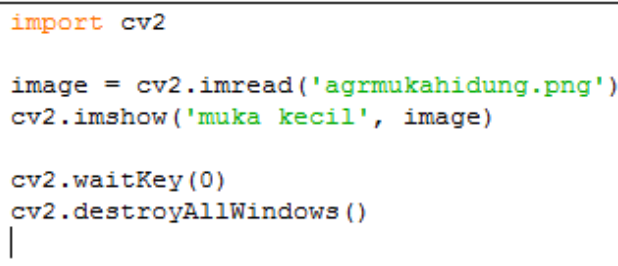

Gambar Algoritma hasil muka depan anggora

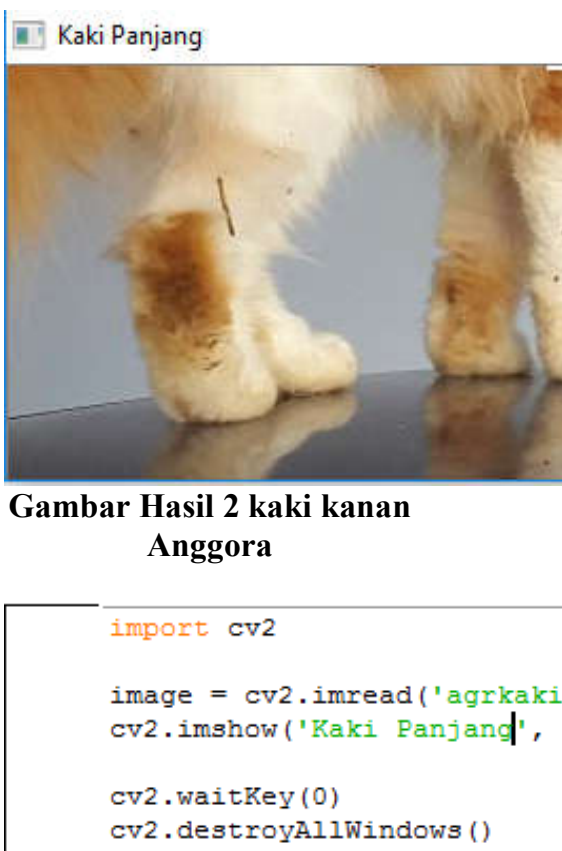

Gambar Algoritma Hasil Kaki Kanan Anggora 


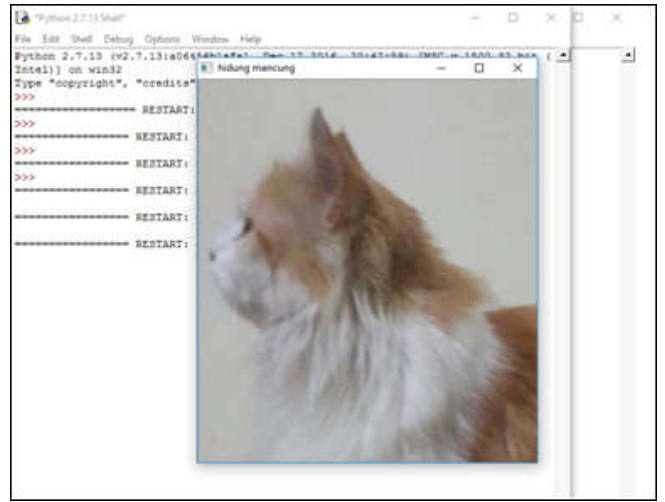

Gambar Hasil 3 Hidung kiri Anggora

import cv2
image = cv2.1mread ('agrmukahidungkir1.png' b
cv2.imshow ('hidung mancung', image)
cv2. waitKey (0)
cv2.destroyAllwindows ()

Gambar Algoritma Hidung Kiri Anggora

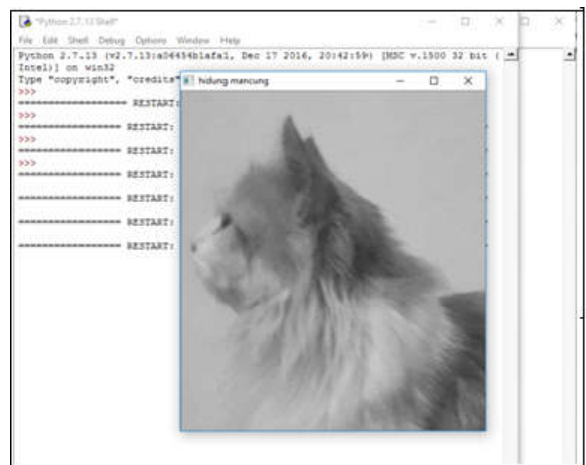

Gambar Hasil Grayscale Anggora

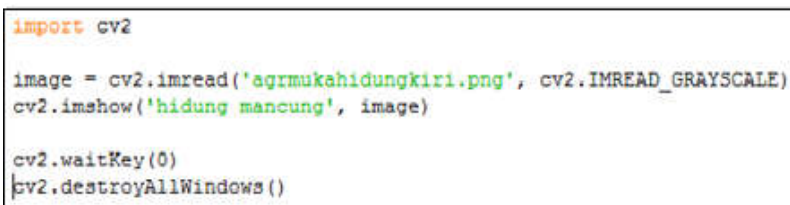

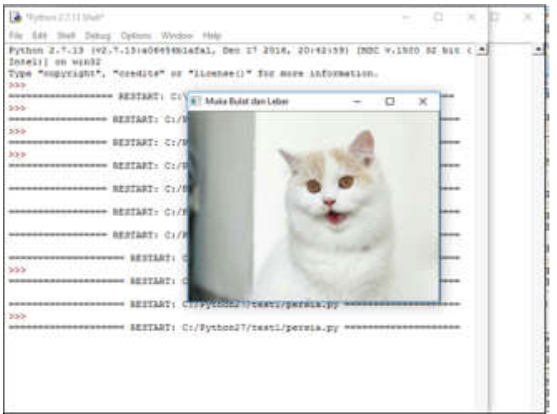

Gambar Hasil 1 muka depan Persia

import cv2

image = cv2.imread ('mukadepan.png') cv2.imshow ('Muka Bulat dan Lebay', image)

cv2 . waitKey (0)

cv2. destroyAllWindows ()

\section{Gambar Algoritma Hasil Muka Depan Persia}

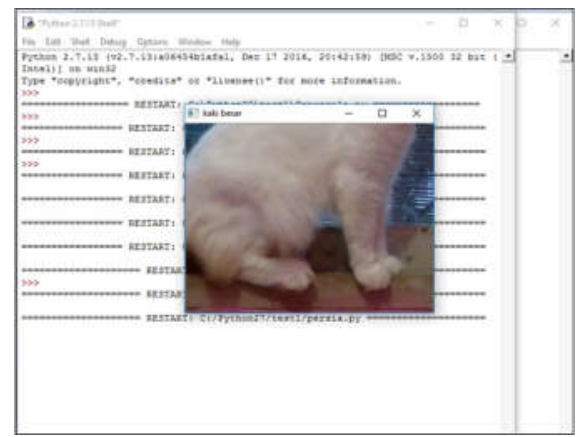

\section{Gambar Hasil 2 Kaki kanan Persia}

import cv2

image $=\mathrm{cv} 2$.imread ('persiakakikanan.png' $)$ cv2.imshow ('kaki besar', image)

kv2. waitKey (0)

cy2. destroyAl1Windows ()

\section{Gambar Algoritma Hasil Grayscale Anggora}

Gambar Algoritma Hasil Kaki kanan Persia 


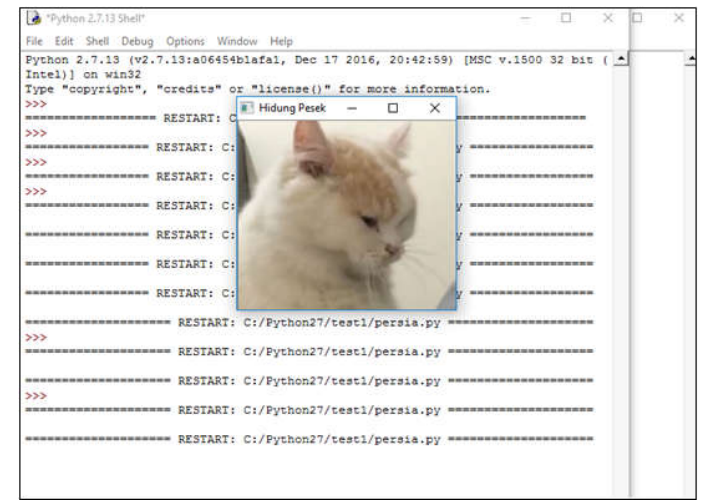

Gambar Hasil 3 Hidung kanan Persia

\section{Kesimpulan}

Berdasarkan hasil dari analisis dan pengujian maka di dapatkan bahwa :

1. Metode Viola-Jones dan HaarCascade dapat diimplementasikan dalam pendeteksian mengenali bentuk wajah jenis kucing Anggora dan persia.

2. Untuk menerapkan image sebagai objek penulis mengcapture gambar yang ingin di olah di OpenCV lalu gambar akan dibandingkan di dataset dengan LBPH jika ada yang mendekati maka akan menampilkan hasil gambar deteksi.

3. Sistem dapat mendeteksi adanya beberapa bentuk wajah kucing dalam suatu citra.

\section{DAFTAR PUSTAKA}

import cv2

image $=c v 2$.imread ("persiamukahidungkanan.png") cv2.imshow('Hidung Peseld', image)

cv2.waitKey (0)

cv2. destroyAllWindows()

\section{Gambar Algoritma Hasil Hidung Kanan Persia}

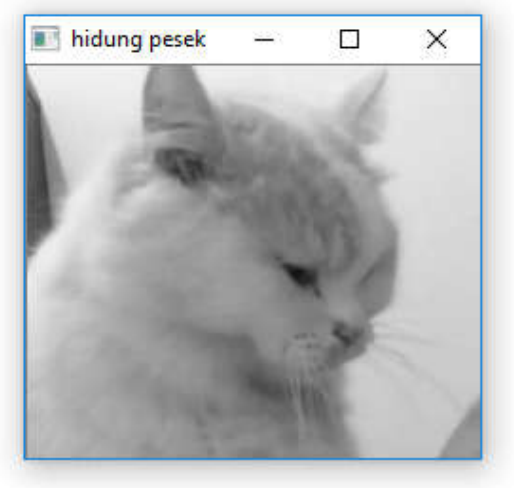

Gambar Hasil Grayscale Persia

import cv2
image = cv2.imread ('persiamukahidungkanan.png', cv2.IMREAD_GRAYSCALA)
cv2.imshow ('hidung pesek', image)
cv2.waitKey (0)
cv2.destroyAl1windows ()

\section{Gambar Algoritma Hasil Grayscale Persia}

Andi. (2016). Pengolahan Citra Digital : Konsep dan Teori. (F. A. Hermawat, Ed.) Aplikasi Pengolahan Citra Digital Meat Detection dengan Metode segmentasi k-mean berbasis opencv .

Budi, P. 2011). Adobe Photoshop CS. Jakarta: Elex Media Komputindo.

Cornelis, R. C. (2012). Python as a Federation Tool for GENESIS 3.0. London

H.Ren., C.-I. C. (2000). An Experiment-Based Quantitative and Comparative Analysis of Target Detection and Image Classification Algoritms for Hyperspectral Imagery. on Geosciene and Remote Sensing: IEEE Trans.

Kristanto, A. (2013). Perancangan Sistem Informasi dan Aplikasi. Yogyakarta: Gava Media.

Marakas, O. d. (2009). Pengertian Sistem. Bandung: Informatika.

Munir, R. (2010). “Warna,” dalam Pengolahan Citra Digital. Bandung.

Munir, R. (2011). Algoritma dan Pemrograman (rev. ed.). Bandung: Informatika.

Mustakini. (2013). Definisi Sistem Informasi. Jakarta: Pengolahan Sistem informasi.

Prasojo, M. (2011). Pengertian Sistem informasi. Surabaya: Jelajah Informasi.

Rezaei, M. (2013). Creating a Cascade of Haar-Like Classifiers: Step by Step. Aplikasi Pendeteksian Ras kucing dengan mendeteksi wajah kucing dengan metode viola jones. 
Santoso. (2010). Open Source. Jogja: Open Source Software.

Sawyer, W. d. (2014). Definisi sistem Informasi. IEE Trans: IEE Trans.

Sutabri. (2012). Analisa Sistem Informasi. Malang: Media Komputindo.

Team, O. D. (2013). About OpenCV. Retrieved April 5, 2013, from Open CV: www.opencv.org/about.html
Wahyudi, E. (2011). Perbandingan Unjuk Kerja Pengenalan Wajah Berbasis Fitur Local Binary Pattern dengan Algoritma PCA dan Chi Square. . Surabaya.

Wijaya, S. A. (2014). Perbandingan Metode Pengenalan Wajah Secara Real Time. malang.

Yakub, M. D. (2012). Data Informasi dalam ilmu komputer. Bandung: Jelajah Informasi. 